\title{
Genetic diversity and multiplicity of Plasmodium falciparum
}

\section{merozoite surface protein $\mathbf{2}$ in field isolates from Sudan}

\section{[version 1; peer review: 1 not approved]}

\author{
Shaza O. Mustafa1,2, Muzamil M. Abdel Hamid (D)2, Mariam A. Aboud3', \\ Mutaz Amin (1D), Mohamed S. Muneer (D2,4, Kyakonye Yasin2,5, \\ Nouh S. Mahgoub (10)6, Nabiela M. El Bagir7 \\ ${ }^{1}$ Faculty of Education, Nile Valley University, Khartoum, Sudan \\ ${ }^{2}$ Department of Parasitology and Medical Entomology, Institute of Endemic Diseases, University of Khartoum, Khartoum, Sudan \\ ${ }^{3}$ Faculty of Science, Al-Neelain University, Khartoum, Sudan \\ ${ }^{4}$ Faculty of Medicine, University of Khartoum, Khartoum, Sudan \\ ${ }^{5}$ Faculty of Pharmacy, International University of Africa, Khartoum, Sudan \\ ${ }^{6}$ Department of Parasitology and Medical Entomology, Nile College, Khartoum, Sudan \\ ${ }^{7}$ Faculty of Veterinary Medicine, University of Khartoum, Khartoum, Sudan
}

V1 First published: 02 Oct 2017, 6:1790

https://doi.org/10.12688/f1000research.12585.1

Latest published: 02 Oct 2017, 6:1790

https://doi.org/10.12688/f1000research.12585.1

\section{Abstract}

Background: Malaria is a major health problem, with over one third of worldwide populations currently at risk. Determining the genetic diversity of plasmodium parasites is essential for assessing the efficacy of antimalarial drugs and for future vaccine development. This study investigated the genetic diversity of $P$. falciparum merozoite surface protein 2 (MSP2), and multiplicity of infection (MOI) in different geographic regions in Sudan.

Methods: A total of 271 patients with uncomplicated malaria were recruited from four ecological sites during malaria transmission season, 2011-2013. P. falciparum was confirmed using species specific primers targeting the rDNA gene. All $P$. falciparum positive samples were genotyped for the major MSP2 allelic families (IC1/3D7 and FC27 MSP2 allele) using nested PCR. Multiplicity of infection and allele frequencies were determined.

Results: A total of 241 samples (88.9\%) were confirmed positive for $P$. falciparum. The number of different MSP2 alleles were 14, 15, 13 and 12 in Khartoum, Gezira, River Nile and Red Sea states, respectively. The 3D7 allelic family was more prevalent in the states of Khartoum, Gezira, River Nile and Red Sea compared to the FC27 allelic family. Multiclonal infections were observed in $25.8 \%$ of patients, with a mean multiplicity of infection (MOI) of 1.45. MOIs were highest in the age group over 40, with an average of 2 and 1.68 in Khartoum and Gezira states, respectively, however MOIs in River Nile and Red Sea states

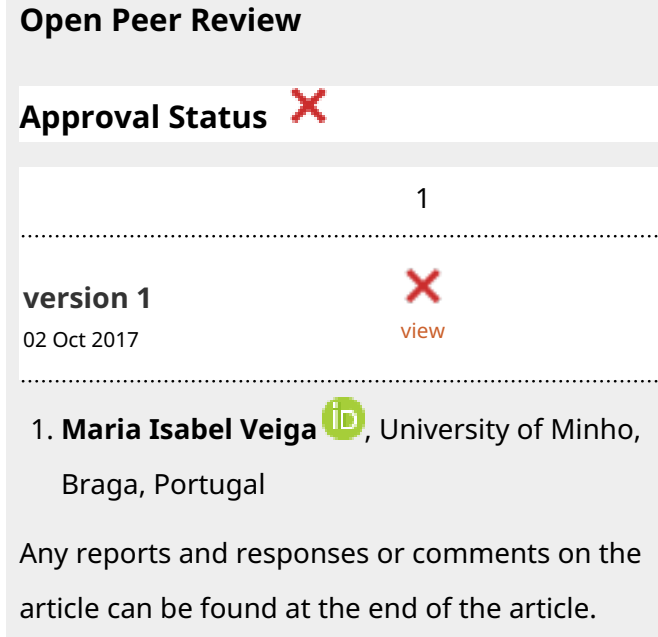


were higher in age groups below 18, with an average of 1.37 and 1.33 ,

respectively.

Conclusions: MSP2 allelic genotyping revealed MOI and diversity of the Sudanese $P$. falciparum isolates. The results of our study are expected to influence current and future malaria control strategies, since the MOI predicts development of clinical malaria and subsequent efficacy of antimalarial treatment.

Keywords

malaria, Plasmodium, falciparum, multiplicity of infection, allele, msp2, Sudan

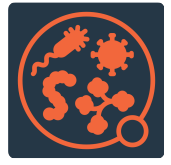

This article is included in the Pathogens

gateway.

\section{Corresponding author: Muzamil M. Abdel Hamid (mahdi@iend.org)}

Author roles: Mustafa SO: Conceptualization, Investigation, Methodology; Abdel Hamid MM: Conceptualization, Funding Acquisition, Project Administration, Supervision, Writing - Review \& Editing; Aboud MA: Formal Analysis, Validation; Amin M: Writing - Original Draft Preparation, Writing - Review \& Editing; Muneer MS: Formal Analysis, Investigation, Methodology; Yasin K: Writing - Review \& Editing; Mahgoub NS: Data Curation, Formal Analysis, Investigation, Methodology; El Bagir NM: Conceptualization

Competing interests: All authors have declared that they have no conflict of interest.

Grant information: This study was partially funded by the National Malaria Program Administration, Ministry of Health, the University of River Valley, Sudan and Third World Academy of Science (TWAS), Trieste, Italy [project no. 13-145 RG/BIO/AF/AC_G].

The funders had no role in study design, data collection and analysis, decision to publish, or preparation of the manuscript.

Copyright: @ 2017 Mustafa SO et al. This is an open access article distributed under the terms of the Creative Commons Attribution License, which permits unrestricted use, distribution, and reproduction in any medium, provided the original work is properly cited. Data associated with the article are available under the terms of the Creative Commons Zero "No rights reserved" data waiver (CC0 1.0 Public domain dedication).

How to cite this article: Mustafa SO, Abdel Hamid MM, Aboud MA et al. Genetic diversity and multiplicity of Plasmodium falciparum merozoite surface protein $\mathbf{2}$ in field isolates from Sudan [version 1; peer review: 1 not approved] F1000Research 2017, 6:1790 https://doi.org/10.12688/f1000research.12585.1

First published: 02 Oct 2017, 6:1790 https://doi.org/10.12688/f1000research.12585.1 


\section{Introhduction}

Malaria was and still is a major health problem, with over one third of worldwide populations being at risk (World Health Organization, 2015). The burden of this disease falls the heaviest on Sub-Saharan African countries (World Health Organization, 2015). In Sudan, almost $90 \%$ of the population live under high malaria transmission levels, as recently reported by the WHO ("WHO | Sudan," 2016; World Health Organization, 2015). Malaria in Sudan is transmitted mainly by Anopheles arabiensis and the majority of cases are due to P. falciparum (Ageep et al., 2009). The merozoite surface protein-2 (MSP2) is a highly polymorphic plasmodium membrane protein and the most expressed in the surface of the merozoite (Gerold et al., 1996). It has been long studied in vaccine trials for being accessible by the immune system (McCarthy et al., 2011). MSP2 protein is highly polymorphic, which gives an opportunity for molecular epidemiologists to differentiate between recurrent and new infections (Mwingira et al., 2011). Genetic diversity of MSP2 alleles is due to mutations and proliferation of highly polymorphic central repeats (Ferreira \& Hartl, 2007). The allelic diversity of MSP2 proteins can be used to calculate multiplicity of infection (MOI), which is the number of different strains of $P$. falciparum coinfecting the same host and is a valuable for estimating malaria transmission level (Vafa et al., 2008). Sudan experiences a range of climate variations, from arid desert in the north, to tropical areas in the south and a short rainy season (Noor et al., 2012). The current study aimed to determine the level of genetic diversity of the $P$. falciparum MSP2 gene, using field isolates across different geo-ecological regions in Sudan. The study also aimed to determine the relationship between genetic diversity and the characteristics between different patients. Little has been documented regarding the molecular diversity of $P$. falciparum in hypo and meso-endemic regions of Sudan, in particular after adoption of ACT as antimalarial treatment.

\section{Methods}

\section{Study areas}

This study was conducted across the two geographical zones of Sudan: the semi-desert regions of the Red Sea (Northeast) and the savannah regions of Khartoum (Central), Gezira and River Nile states. It took place between August 2011 and December 2013 - peak malaria transmission is between July and December (rainy season) in the poor and rich savannah regions, but in the semi desert regions of the Red Sea, peak malaria transmission occurs between November and January, during the winter season.

\section{Ethical statement}

Ethical clearance was obtained from the scientific and research ethics committee, Institute of Endemic Diseases, University of Khartoum. Informed consent was obtained from patients, or guardians if the patient was a minor, for participation in this study. Anonymity and confidentiality of patient information were maintained throughout.

\section{Sample collection and parasite identification}

A total of 271 symptomatic malaria patients from all age groups regardless of gender were recruited from selected health facilities
(Omdurman teaching hospital and Omdoom and Mubarak Zaroog health centers in Khartoum, Wad madani teaching hospital in Gezira, Zeedab, Kaboushia and Elbouga hospitals in River Nile and Unity hospital in Red Sea) during peak malaria transmission season. Patients were passively recruited from the outpatient clinics of these hospitals during the study period. Patients were diagnosed with malaria using blood film microscopy. Parasite density and hemoglobin level were measured on each sample upon collection. Thick and thin blood smears were stained with Giemsa stain. Parasite density was determined by counting the number of asexual parasites per 200 white blood cells using the formula described by Cook (Cook, 1990). The data was grouped based on the level of parasitemia, into low $=1-5,000$ parasites $/ \mu 1$, intermediate $=5,001-10,000$ parasites $/ \mu \mathrm{l}$ and high $=>10,000$ parasites $/ \mu 1$.

\section{DNA extraction and amplification of MSP2 genes}

Parasite DNA was extracted from dried blood samples spotted on filter papers using a method described by Musapa et al. (Musapa et al., 2013). Plasmodium species were identified by $18 \mathrm{~S}$ rDNA based nested PCR, using genus and species specific primers manufactured by Macrogen, Korea, as described by Snounou et al. [15]. Msp2 alleles were further amplified with slight modification of the standardized nested-PCR protocols described previously by Snounou et al. (Snounou et al., 1993)

\section{Electrophoresis and visualization of PCR products}

The amplified PCR products were run on $2 \%$ Agarose gel (Caisson, Utah, USA) stained with $4 \mu$ ethidium bromide at $100 \mathrm{~V}$ and $30 \mathrm{~A}$ for 60 minutes. DNA fragments were estimated using 100 bp DNA ladder marker (Vivantis, Selangor DarulEhsan, Malaysia) and the bands were viewed under UV light using trans-illuminator (BioDoc-It UVP, Cambridge, UK).

\section{Calculating the multiplicity of infection}

The multiplicity of infection (MOI) was calculated by dividing the total number of fragments observed in MSP2 by the number of positive samples. Isolates with a single genotype were considered monoclonal infections while isolates with more than one genotype was considered multiclonal infections.

\section{Statistical analysis}

Data was analyzed using SPSS version 20 (SPSS, Inc., Chicago, IL, USA). Proportions were compared for significance using the $\chi 2$-test. The association between MOIs, parasite densities and age groups were computed using Spearman's rank correlation coefficient. Statistical significance among MOIs and mean hemoglobin levels for the different age groups were calculated using the Kruskal-Wallis H-test at a $P$-value of $\leq 0.05$.

\section{Results}

P. falciparum rDNA was detected in a total of $241(88.9 \%)$ malaria patients using nested PCR (Figure 1). 158 (65.6\%) were male, while $83(34.4 \%)$ were female. The distribution of patients across the four studied states: Khartoum, Gezira, River Nile and the Red Sea was $81(33.6 \%), 58(24.1 \%), 47(19.5 \%)$ and 55 
(22.8\%), respectively. The age groups ranged between 3-90 years, with a mean of $31.39 \pm 14.9$ years. The mean parasite density was higher in the River Nile state (15869 parasites/ $\mu \mathrm{l})$ compared to Khartoum, Gezira, and Red Sea states (14563, 11266, and 14603 parasites/ $\mu \mathrm{l}$, respectively), and this difference was statistically significant $(\mathrm{p}$-value $=0.02)$. The mean hemoglobin level was lowest in Khartoum $(5.23 \mathrm{~g} / \mathrm{dl})$ compared to the other regions; Gezira, River Nile, and Red Sea (7.94, 9.26, and 7.74 g/dl, respectively), and the difference was statistically significant ( $\mathrm{p}$-value $=$ 0.02) (Table 1).

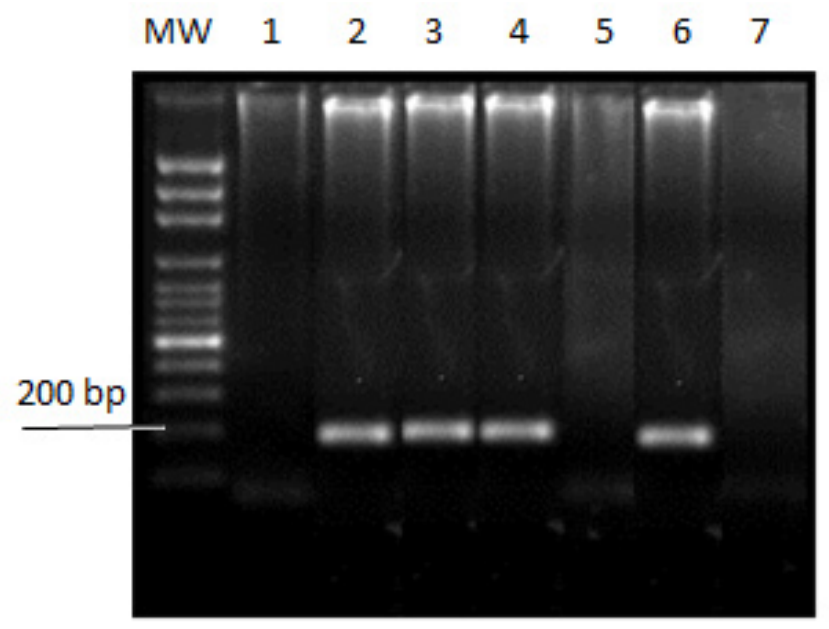

Figure 1. Detection of $\boldsymbol{P}$ falciparum species. Amplification of the $P$. falciparum ribosomal DNA gene using genus and species specific primers by nested PCR, yielding amplicons of $220 \mathrm{bp}$ in size.) Molecular weight marker (MW) is $100 \mathrm{bp}$ (iNTRON, Inc.). Lanes 2, 3,4 , and 6 are positive for samples of $P$. falciparum; 1 and 5 are negative for samples of $P$. falciparum; lane 7 is the negative control.
Allelic polymorphism of MSP2, multiplicity of infection, distribution of multiclonal $P$. falciparum infection, and parasite density across different age groups in Sudan Allele genotyping revealed the highly polymorphic nature of Sudanese $P$. falciparum isolates with respect to the MSP2 gene. Both IC1/3D7 and FC27 MSP2 allele types were identified (Figure 2). The total number of different sized alleles detected in this study was 42. Among them IC1/3D7 (160-400 bp) and FC27 (140-400 bp) allele families were noted. Frequencies of different MSP2 alleles and their combinations and multiplicity of infection across the study sites are shown in Table 2. The frequency of samples with only IC1/3D7 and FC27 were 56.4\% (136/241), and $17 \%(41 / 241)$, respectively and IC1/3D $7 /$ FC27 combinations were found in $26.6 \%(64 / 241)$ of samples. The prevalence of IC1/3D7 and FC27 allelic types was $82.9 \%$ (200/241) and $43.5 \%$ $(105 / 241)$, respectively. Multiple clones were detected in all study sites. Multiplicity of infection (MOI) was highest in P. falciparum infected patients from Gezira state (1.67 genotypes per infection) and lowest in those from Red Sea state (1.20 genotypes per infection) and it was statistically significant, $(\mathrm{p}$-value $=0.001)$ (Table 2). The difference in distribution of allelic polymorphism of MSP2 was only significant for total MSP2 and FC27 ( $\mathrm{p}$-value $=0.002$ and $\mathrm{p}$-value $=0.042$, respectively $)$. However, for IC1/3D7 the result was not statistically significant ( $p$-value $=0.89$ ). The estimated mean MOI of all studied areas was 1.46 genotypes per infection (Table 2). There was a negative correlation between age and parasite density (Spearman rank coefficient $=0.03$; p-value $=0.65$ ), though it was not significant. The $18-40$ age group had the highest mean parasite density (16354 parasites/ $\mu$ l, Table 3 ).

Relationship between multiplicity of infection, age groups and parasite densities

The distributions of $P$. falciparum MSP2 block 3 allelic types across different age groups are shown in Table 3. The prevalence of IC1/3D7 and FC27 is shown in the same table.

Table 1. Population characteristics of $P$. falciparum infected patients from different study sites in Sudan.

\begin{tabular}{|c|c|c|c|c|c|}
\hline \multirow{3}{*}{ Characteristics } & Khartoum & Gezira & River Nile & Red Sea & Total \\
\hline & $n=81$ & $n=58$ & $n=47$ & $n=55$ & $n=241$ \\
\hline & $n(\%)$ & $n(\%)$ & $n(\%)$ & $n(\%)$ & $n(\%)$ \\
\hline \multicolumn{6}{|l|}{ Gender } \\
\hline Male & $51(62.9)$ & $34(58.6)$ & $32(68.1)$ & $41(74.5)$ & $158(65.6)$ \\
\hline Female & $30(37.1)$ & $24(41.4)$ & 15(31.9) & $14(25.5)$ & $83(34.4)$ \\
\hline \multicolumn{6}{|l|}{ Age Group } \\
\hline$<18$ & $16(19.8)$ & $5(8.6)$ & $8(17.0)$ & $5(9.1)$ & $34(14.1)$ \\
\hline $18-40$ & $55(67.9)$ & $37(63.8)$ & $32(68.1)$ & $32(58.2)$ & $156(64.7)$ \\
\hline$>40$ & $10(12.3)$ & $16(27.6)$ & $7(14.9)$ & 18(32.7) & $51(21.2)$ \\
\hline $\begin{array}{l}\text { mean parasitemia } \\
\text { cell/ } \mu l\end{array}$ & 14562.6 & 11266.2 & 15869.1 & 14603.3 & \\
\hline $\begin{array}{l}\text { mean TWBCs } \\
\text { cell/ } / \mu l\end{array}$ & 5034.4 & 5145.6 & 7018.6 & 3887.5 & \\
\hline mean $\mathrm{Hb}$ g/dl & 5.23 & 7.94 & 9.26 & 7.74 & \\
\hline
\end{tabular}




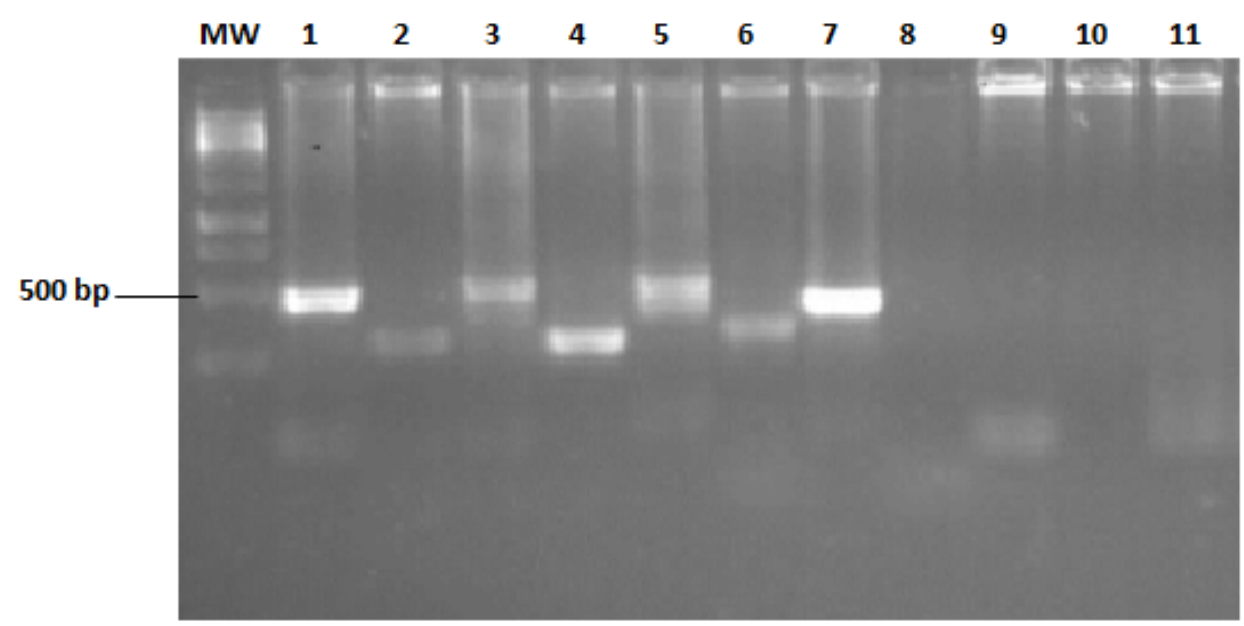

Figure 2. PCR genotyping of MSP2 polymorphic alleles. PCR typing of MSP2 multiple clones (FC27) band size range (250-400 bp) and (IC1/3D7) band size range (500-750 bp). MW: 100 bp ladder (iNTRON, Biotechology). Lanes 1, 3 and 7 are positive for IC1/3D7, lane 9 is negative for the IC1/3D7 allelic family. Lanes 2, 4, and 6 are positive for the FC27 allelic family, 8 is negative for FC27 and lane 11 is a negative control. Lane 5 is positive for IC1/3D7, showing multiple clones (500 and 600 bp).

\section{Table 2. MSP2 block 3 allelic type frequencies and multiplicity of infection of $P$. falciparum isolates from different study sites in Sudan.}

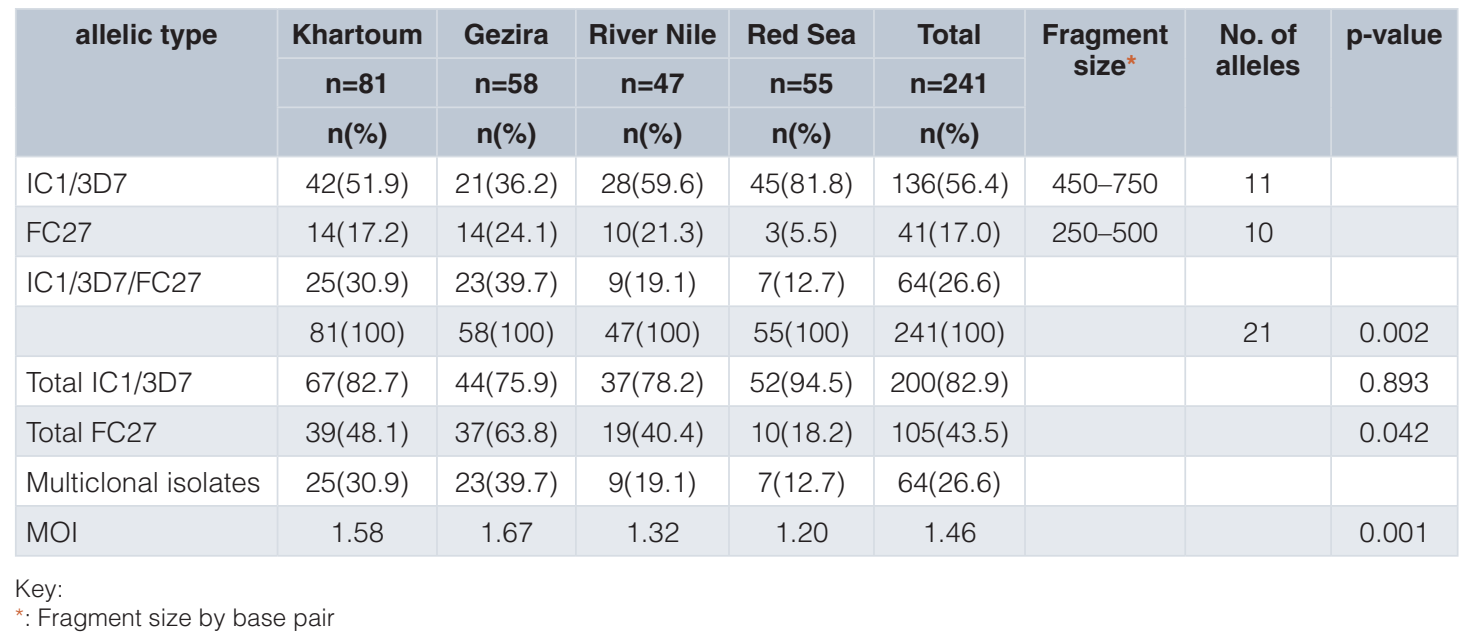

Table 3. Distribution of MSP2 block 3 allelic types among age groups of $P$. falciparum infected patients from Sudan.

\begin{tabular}{|c|c|c|c|c|}
\hline \multirow{4}{*}{ allelic type } & \multicolumn{4}{|c|}{ age groups } \\
\hline & $<18$ & $18-40$ & $>40$ & Total \\
\hline & $\mathrm{n}=34$ & $n=156$ & $n=51$ & $n=241$ \\
\hline & $n(\%)$ & $n(\%)$ & $n(\%)$ & $n(\%)$ \\
\hline IC1/3D7 & $20(58.8)$ & $86(55.1)$ & $30(58.8)$ & 136(56.4) \\
\hline FC27 & $3(8.8)$ & $31(19.9)$ & $7(13.7)$ & $41(17.0)$ \\
\hline IC1/3D7/FC27 & 11(32.4) & $39(25.0)$ & $14(27.5)$ & $64(26.6)$ \\
\hline Total IC1/3D7 & $31(91.1)$ & 125(80.1) & $44(86.3)$ & 200(82.9) \\
\hline Total FC27 & 14(41.1) & $70(44.9)$ & $21(41.1)$ & 105(43.5) \\
\hline Multiclonal isolates & $11(32.4)$ & $39(25.0)$ & $14(27.5)$ & $64(26.6)$ \\
\hline $\mathrm{MOI}$ & 1.50 & 1.44 & 1.52 & 1.46 \\
\hline
\end{tabular}

There is no significant correlation between multiplicity of infection and the age group the patient is in (Spearman rank coefficient $=0.01 ; P$-value $=0.50)$. The distribution of IC1/3D7 and FC27 according to different levels of parasitaemia is shown in Table 4. Neither the individual distribution of IC1/3D7and FC27 nor the multiclonal isolates were significantly different among different parasitaemic groups $(\mathrm{p}$-value $=0.7$ and $\mathrm{p}$-value $=0.957$, respectively).

Dataset 1. Raw data supporting the findings presented in this study

http://dx.doi.org/10.5256/f1000research.12585.d179181

The dataset is available both in XLSX and SPPS format. 


\begin{tabular}{|c|c|c|c|c|}
\hline \multirow{4}{*}{ allelic type } & \multicolumn{3}{|c|}{ parasitaemia* } & \multirow[b]{2}{*}{ Total } \\
\hline & $1-5000$ & $5001-10000$ & $>10000$ & \\
\hline & $n=98$ & $\mathrm{n}=58$ & $\mathrm{n}=85$ & $n=241$ \\
\hline & $n(\%)$ & $n(\%)$ & $n(\%)$ & $n(\%)$ \\
\hline IC1/3D7 & $44(44.9)$ & $41(70.7)$ & $51(60.0)$ & $136(56.4)$ \\
\hline FC27 & $25(25.5)$ & $4(6.9)$ & $12(14.1)$ & $41(17.0)$ \\
\hline IC1/3D7/FC27 & $29(29.6)$ & 13(22.4) & $22(25.9)$ & $64(26.6)$ \\
\hline Total IC1/3D7 & $73(74.5)$ & $54(93.1)$ & $73(85.9)$ & $200(82.9)$ \\
\hline Total FC27 & $54(55.1)$ & 17(29.3) & $34(40.0)$ & $105(43.5)$ \\
\hline Multiclonal isolates & $29(29.6)$ & 12(20.7) & $22(25.9)$ & $64(26.6)$ \\
\hline $\mathrm{MOI}$ & 1.50 & 1.40 & 1.43 & 1.46 \\
\hline
\end{tabular}

\section{Discussion}

Increasing our knowledge of the genetic diversity of $P$. falciparum induced malaria will certainly help us understand its pathogenesis, acquired immunity and drug resistance. 14, 15, 13 and 12 different alleles of MSP2 were identified in Khartoum, Gezira, River Nile and Red Sea states, respectively. This data is consistent with previous studies in low and unstable malaria transmission regions in eastern Sudan (A-Elbasit et al., 2007), central Sudan (Hamid et al., 2013), and other areas of seasonal unstable malaria transmission (Elmahdi et al., 2012). 3D7 alleles were more prevalent in the four states (Khartoum, Gezira, River Nile and Red Sea) compared to FC27 alleles. This finding differs from those of previous studies in central and eastern Sudan, where FC27 was the most predominant allelic family (A-Elbasit et al., 2007; Babiker et al.,1997; Hamid et al., 2013). In our study, 25\% of studied samples were found to have mixed infections with multiple parasite clones; a result similarly reported in eastern Sudan (Babiker, 1998).

In our study, multiplicity of infection was highest in the $>40$ age group (with an average MOI of 2 and 1.68 in Khartoum and Gezira states, respectively), whereas the MOI was highest in the $<18$ age group (with an average of 1.37 and 1.33 in River Nile and Red Sea states, respectively), although the difference was not statistically significant. Recent studies on the variation of MOI with age have suggested that the influence of age on MOI is highly affected by the endemicity of malaria (Pinkevych et al., 2015). this is consistent with studies that have shown an age-dependent MOI in villages with intense perennial malaria transmission (Smith et al., 1999) and some areas with hypo-meso-endemic malaria transmission like Ghana (Agyeman-Budu et al., 2013),

The relatively higher number of alleles detected at high parasite densities might also mean that more diverse parasite populations are present in such infections. This suggestion is partly supported by the finding that all the different allelic types were more often concurrently detected in the high-density samples
(Färnert et al., 2001). The present study reported that the increasing level of multiplicity was seen with increased parasite density of the samples. These findings are compatible with a previous study that has shown a clear trend of increasing parasite density with increased multiplicity for genetic markers on both genes, MSP1 and MSP2 (Peyerl-Hoffmann et al., 2001). The results of our study will likely influence current and future malaria control strategies since MOI can predict antimalarial treatment response (Kyabayinze et al., 2008).

\section{Conclusions}

Allele genotyping revealed the highly polymorphic nature of Sudanese $P$. falciparum isolates with respect to the MSP2 gene. The results of our study are expected to have an influence on the current and future malaria control strategies, since MOI predicts development of clinical malaria and subsequent efficacy of antimalarial treatment.

\section{Abbreviations}

MSP2: merozoite surface protein 2, PCR: polymerase chain reaction, MOI: multiplicity of infection, ANOVA: analysis of variance, WHO: World Health Organization, rDNA: ribosomal DNA, ACT: artemisinin based combination therapy.

\section{Ethical statement}

The study received approval from the scientific and research ethics committee of the Institute of Endemic Diseases; University of Khartoum, Sudan. Informed consent was obtained from all participants (or from the parents/legal guardians when the participant was a minor), prior to their enrolment. All malaria patients approached in the study were treated using the standard treatment of WHO protocol for malaria (Olumese, 2017).

\section{Data availability}

Dataset 1: Raw data supporting the findings presented in this study. The dataset is available both in XLSX and SPPS format. DOI, 10.5256/f1000research.12585.d179181 (Mustafa et al., 2017).

Competing interests

All authors have declared that they have no conflict of interest.

Grant information

This study was partially funded by the National Malaria Program Administration, Ministry of Health, the University of River Valley, Sudan and Third World Academy of Science (TWAS), Trieste, Italy [project no. 13-145 RG/BIO/AF/AC_G].

The funders had no role in study design, data collection and analysis, decision to publish, or preparation of the manuscript.

\section{Acknowledgements}

We thank all malaria patients who participated in the study. The authors would also like to thank Prof. Muntaser E. Ibrahim, director of the Dr. Douglas Barker Molecular Biology Lab, Institute of Endemic Diseases, University of Khartoum, for hosting the molecular work and data analysis. 
A-Elbasit IE, EIGhazali G, A-Elgadir TME, et al.: Allelic polymorphism of MSP2 gene in severe $P$. falciparum malaria in an area of low and seasonal transmission. Parasitol Res. 2007; 102(1): 29-34.

PubMed Abstract | Publisher Full Text

Ageep TB, Cox J, Hassan MM, et al.: Spatial and temporal distribution of the malaria mosquito Anopheles arabiensis in northern Sudan: influence of environmental factors and implications for vector control. Malar J. 2009; 8: 123. PubMed Abstract | Publisher Full Text | Free Full Text

Agyeman-Budu A, Brown C, Adjei G, et al.: Trends in multiplicity of Plasmodium falciparum infections among asymptomatic residents in the middle belt of Ghana. Malar J. 2013; 12: 22.

PubMed Abstract | Publisher Full Text | Free Full Text

Babiker HA: Unstable malaria in Sudan: the influence of the dry season. Plasmodium falciparum population in the unstable malaria area of eastern Sudan is stable and genetically complex. Trans R Soc Trop Med Hyg. 1998; 92(6): 585-9.

PubMed Abstract | Publisher Full Text

Babiker HA, Lines J, Hill WG, et al:: Population structure of Plasmodium falciparum in villages with different malaria endemicity in east Africa.

Am J Trop Med Hyg. 1997; 56(2): 141-7.

PubMed Abstract | Publisher Full Tex

Cook GC: Parasitic Disease in Clinical Practice. London: Springer London, 1990. Publisher Full Text

Elmahdi ZA, Nugud AA, Elhassan IM: Estimation of malaria transmission intensity in Sennar state, central Sudan. East Mediterr Health J. 2012; 18(9): 951-6.

PubMed Abstract

Färnert A, Arez AP, Babiker HA, et al.: Genotyping of Plasmodium falciparum infections by PCR: a comparative multicentre study. Trans $R$ Soc Trop Med Hyg. 2001; 95(2): 225-32.

PubMed Abstract | Publisher Full Text

Ferreira MU, Hartl DL: Plasmodium falciparum: Worldwide sequence diversity and evolution of the malaria vaccine candidate merozoite surface protein-2 (MSP-2). Exp Parasitol. 2007; 115(1): 32-40.

PubMed Abstract | Publisher Full Text

Gerold P, Schofield L, Blackman MJ, et al.: Structural analysis of the glycosylphosphatidylinositol membrane anchor of the merozoite surface proteinsand -2 of Plasmodium falciparum. Mol Biochem Parasitol. 1996; 75(2): 131-43. PubMed Abstract | Publisher Full Text

Hamid MM, Mohammed SB, El Hassan IM: Genetic Diversity of Plasmodium falciparum Field Isolates in Central Sudan Inferred by PCR Genotyping of Merozoite Surface Protein 1 and 2. N Am J Med Sci. 2013; 5(2): 95-101. PubMed Abstract | Publisher Full Text | Free Full Text

Kyabayinze DJ, Karamagi C, Kiggundu M, et al.: Multiplicity of Plasmodium falciparum infection predicts antimalarial treatment outcome in Ugandan children. Afr Health Sci. 2008; 8(4): 200-5.

PublMed Abstract | Free Full Text
McCarthy JS, Marjason J, Elliott S, et al.: A phase 1 trial of MSP2-C1, a bloodstage malaria vaccine containing 2 isoforms of MSP2 formulated with Montanide® ISA 720. PLoS One. 2011; 6(9): e24413.

PubMed Abstract | Publisher Full Text | Free Full Text

Musapa M, Kumwenda T, Mkulama M, et al.: A simple Chelex protocol for DNA extraction from Anopheles spp. J Vis Exp. 2013; 71: pii: 3281.

PubMed Abstract | Publisher Full Text | Free Full Text

Mustafa SO, Abdel Hamid MM, Aboud MA, et al.: Dataset 1 in: Genetic diversity and multiplicity of Plasmodium falciparum merozoite surface protein $\mathbf{2}$ in field isolates from Sudan. F1000Research. 2017.

Data Source

Mwingira F, Nkwengulila G, Schoepflin S, et al:: Plasmodium falciparum msp1, msp2 and glurp allele frequency and diversity in sub-Saharan Africa. Malar $\mathrm{J}$. 2011; 10(1): 79

PubMed Abstract | Publisher Full Text | Free Full Text

Noor AM, EIMardi KA, Abdelgader TM, et al:: Malaria risk mapping for control in the republic of Sudan. Am J Trop Med Hyg. 2012; 87(6): 1012-21.

PubMed Abstract | Publisher Full Text | Free Full Text

Olumese P: (n.d.). FOR THE TREATMENT OF MALARIA GUIDELINES WHO Library Cataloguing-in-Publication Data. 2017

Reference Source

Peyerl-Hoffmann G, Jelinek T, Kilian A, et al: Genetic diversity of Plasmodium falciparum and its relationship to parasite density in an area with different malaria endemicities in West Uganda. Trop Med Int Health. 2001; 6(8): 607-13. PubMed Abstract | Publisher Full Text

Pinkevych M, Petravic J, Bereczky S, et al: Understanding the relationship between Plasmodium falciparum growth rate and multiplicity of infection. $J$ Infect Dis. 2015; 211(7): 1121-7.

PubMed Abstract | Publisher Full Text

Smith T, Beck HP, Kitua A, et al:: Age dependence of the multiplicity of Plasmodium falciparum infections and of other malariological indices in an area of high endemicity. Trans R Soc Trop Med Hyg. 1999; 93 Suppl 1: 15-20. PubMed Abstract | Publisher Full Text

Snounou G, Viriyakosol S, Jarra W, et al.: Identification of the four human malaria parasite species in field samples by the polymerase chain reaction and detection of a high prevalence of mixed infections. Mol Biochem Parasitol. 1993; 58(2): 283-92.

PubMed Abstract | Publisher Full Text

Vafa M, Troye-Blomberg M, Anchang J, et al:: Multiplicity of Plasmodium falciparum infection in asymptomatic children in Senegal: relation to transmission, age and erythrocyte variants. Malar J. 2008; 7(1): 17.

PubMed Abstract | Publisher Full Text | Free Full Text

WHO | Sudan: 2016; Retrieved December 28, 2016.

Reference Source

World Health Organization: World Malaria Report (2008-2015). 2015; Retrieved August 8, 2016

Reference Source 


\section{Open Peer Review}

\section{Current Peer Review Status: $\mathrm{X}$}

\section{Version 1}

Reviewer Report 05 September 2018

https://doi.org/10.5256/f1000research.13629.r37789

(C) 2018 Veiga M. This is an open access peer review report distributed under the terms of the Creative Commons Attribution License, which permits unrestricted use, distribution, and reproduction in any medium, provided the original work is properly cited.

\section{Maria Isabel Veiga}

Life and Health Science Research Institute (ICVS), University of Minho, Braga, Portugal

The article as it stands, although on an important topic specific for malaria research, needs further improvement to achieve sufficient scientific relevance for indexing. The work describes the diversity of a very polymorphic gene, pfmsp2 in $P$. falciparum in various sites around Sudan adjudicating the multiplicity of infection. They compare the genetic diversity between different regions where samples were collected as well as with patients' characteristics.

Considering the Figure 2, that should represent the results for all the samples, the results are very difficult to extract, questioning the true genotyping and consequently the MOI of the samples. The nested PCR method used is very delicate and demands a good quality of agarose gel pictures, that is not the case of Figure 2. Unless all samples were run in the same gel (which is not the case), the bands from the molecular marker has to be evident to be able to evaluate the band sizes of the samples. The families IC1 and FC27 can differ of just 50 bp difference, making the resolution of the Figure 2 an impossible task to achieve. This technical issues have to be resolved for the accuracy of the data.

In the article should also be described the malaria epidemics in the regions where the samples were collected to understand if the number of samples herein analyzed are representative.

The method to identify plasmodium species is lacking the reference and is not really understood if other species were identified.

Some of the authors of this article have published ${ }^{1}$ before submission of this manuscript a similar study on samples collected in one of the regions herein studied in the same year and the same genotyping of the msp2. They don't mention this publication not even in the discussion section. Are some of the samples overlapping this study?

\section{References}

1. Mustafa S, Abdel Hamid M, Aboud M, Amin M, et al.: Genetic diversity and multiplicity of Plasmodium falciparum merozoite surface protein 2 in field isolates from Sudan. F1000Research. 
2017; 6. Publisher Full Text

Is the work clearly and accurately presented and does it cite the current literature? No

Is the study design appropriate and is the work technically sound?

Partly

Are sufficient details of methods and analysis provided to allow replication by others? Yes

If applicable, is the statistical analysis and its interpretation appropriate? Partly

Are all the source data underlying the results available to ensure full reproducibility? No

Are the conclusions drawn adequately supported by the results? Partly

Competing Interests: No competing interests were disclosed.

Reviewer Expertise: Plasmodium falciparum drug resistance

I confirm that I have read this submission and believe that I have an appropriate level of expertise to state that I do not consider it to be of an acceptable scientific standard, for reasons outlined above.

The benefits of publishing with F1000Research:

- Your article is published within days, with no editorial bias

- You can publish traditional articles, null/negative results, case reports, data notes and more

- The peer review process is transparent and collaborative

- Your article is indexed in PubMed after passing peer review

- Dedicated customer support at every stage

For pre-submission enquiries, contact research@f1000.com

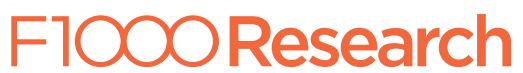

